Voix et Images

\title{
Bibliographie des oeuvres de Yves Thériault
}

\section{Renald Bérubé}

Volume 5, numéro 2, hiver 1980

Yves Thériault

URI : https://id.erudit.org/iderudit/200204ar

DOI : https://doi.org/10.7202/200204ar

Aller au sommaire du numéro

Éditeur(s)

Les Presses de l'Université du Québec

ISSN

0318-9201 (imprimé)

1705-933X (numérique)

Découvrir la revue

Citer ce document

Bérubé, R. (1980). Bibliographie des oeuvres de Yves Thériault. Voix et Images, 5(2), 241-243. https://doi.org/10.7202/200204ar d'utilisation que vous pouvez consulter en ligne.

https://apropos.erudit.org/fr/usagers/politique-dutilisation/ 


\section{gIQLIOGRAPHIE}

\section{CEuvres d'Yves Theriault}

Contes pour un homme seul, (1944), Montréal, Editions HMH, 1965.

Le Marcheur (théátre), (1950). Montréal, Leméac, 1968.

La Fille laide, (1950). Montreal, Editions de Ihomme, 1962.

Le Dompteur d'ours. Montréal, Cercle du livre de France, 1951.

Les Vendeurs du temple. (1951), Montréal, Editions de l'homme. 1964.

La Vengeance de la mer, Montréal, Publication du lapin, 1951.

Lo Samaritain (radio-théâtre), (1952). Montreal, Ecrits du Canada français, tome IV. 1958.

Aaron, (1954 et 1957), Paris, Grasset, $1957^{\circ}$.

- Les ceuvres d'Yves Thériault sont ici présentées selon l'ordre chronologique de leur parution (ou de la date de la première, dans le cas des ceuvres dramatiques). Lorsque l'édition que nous utilisons n'est pas la première, la date de parution de l'cuvre (ou de la première, dans le cas des textes dramatiques) est indiquée entre parenthèses. Il existe souvent, des ceuvres de Thériault, des éditions plus récentes que celles que nous indiquons ici. Celle bibliographie ne retient que les ceuvres publiées de l'auteur; elle ne contient ni ses nombreuses ceuvres (publiées) pour enfants el adolescents, ni les textes dramatiques joués mais non publiés, ni les nouvelles et autres textes qui sont parus dans divers journaux et revues mais n'ont pas été regroupés en volume.

- Aaron a d'abord été publiè a l'Institul littéraire du Québec en 1954, puis dans une édition remaniée et augmentée chez Grasset en 1957. L'édition courante d'Aaron est dorénavant celle de 1957. 
Agaguk, (1958). Montréal, Edittons de l'homme, 1963.

Ashini, Montreal et Paris, Fides, 1960.

Rot de la Cóte Nord (la Vie extraordinaire de Napoléon-Alexandre Comeau), Montreal. Editions de l'hornme, 1960.

Cul-de-sac. Québec, Institut litteraire du Quebec, 1961.

Les Commettants de Carıdad, Quèbec, Institut littéraire du Québec, 1961.

Amour au goül de mer, Montréal, Beauchemin, 1961.

Le Vendeur d'étolles (contes), Montreal el Paris. Fides, 1961.

Séjour à Moscou (chronique de voyage), Montréal el Paris, Fides, 1961

Si la bombe m'était contée (nouvelles el documents), Montréal, Editions du jour, 1962.

Le Grand Roman d'un petit homme. Montreal, Editions du jour, 1963.

Le Ru d'Ikoué, Montréal et Paris, Fides, 1963.

La Rose de pierre (Histoires d'amour), Montreal, Editions du jour, 1964.

Les Temps du carcajou, Paris, Laffont, 1966.

L'Appelante. Montréal, Editions du jour, 1967.

L'lle introuvable (nouvelles), Montréal, Editions du jour, 1968.

Kesten, Montréal, Editions du jour, 1968.

La Mort d'eau, Montréal, Editions de I'homme, 1968.

N'Tsuk, Montréal, Editions de l'homme, 1968.

Mahigan, Montreal, Lemeac. 1968.

Textes et documents, Montréal, Leméac, 1969.

Antoine of sa montagne. Montreal. Editions du jour, 1969.

Tayaout, fils d'Agaguk. Montréal, Editions de l'homme, 1969.

Valérie, Montreal, Editions de l'homme, 1969.

Frédango, suivi de les Terres nouves (théätre). Montréal Lemèac. 1970.

Le Dernier Havre, Montréal, l'Actuelle, 1970.

La Passe-au-Crachin. Montréal, Ferron editeur, 1972.

Le Haut Pays, Montreal, Ferron editeur, 1973.

Agoak (l'Hèritage d'Agaguk), Montrèal. Stanké/Quinze, 1975.

CEuvre de chair (nouvelles), Montréal, Stankè, 1976.

Mor, Plerre Huneau, Montreal, Hurtubise HMH, 1976

\section{Quelques articles et études}

BASILE, Jean, "la Troisıème enfance d'Yves Therıault", lo Cevoir, 17 octobre 1970. p. 17.

BERUBE. Renald, "Yves Theriault ou la lutte de l'homme contre les puissances obscures", dans Livres of auteurs canadiens 1968, p. 15-25.

Id., "Yves Theriaull et la Gaspésie de la mer", dans Possibles, vol. 2, nos 2-3, hiverprintemps 1978, p. 147-165. 
BESSETTE, Gerard, Une littérature en ebullition, Montréal. Editions du jour, 1968. Sur Theriault: "le Primitivisme dans les romans de Theriault". p 109-216.

BROCHU, André, I'instance critique, Montreal, Leméac, 1974. Sur Thériault : " Theriault et la sexualitè" et "Individualité el collectivitè dans Agaguk, Ashıni, et les Commeltants de Caridad". p. 133-205.

DORION, Gilles, et Maurice Emond, "Dossier : Yves Thériault", dans Québec français, no 23, octobre 1976, p. 21-28.

EMOND, Maurice. Yves Therrauit et le combat de lhomme, Montréal, Cahiers du Quebec/Hurtubise HMH, 1973.

Id., "Ashini ou la nostalgie du Paradis perdu". dans Voix et Images du Pays IX. p. 35-62.

GODIN, Jean-Clèo, et Laurent Mailhot, le Théâtre québécois, Montréal, Hurtubise $H M H, 1970$. Sur Thériault : "Voix et pas d'Yves Thériault: lo Samaritain el le Marcheurn, par Laurent Mailhot, p. 59-79.

LARIN, Robert, *Essai de psychocritique d'Agaguk d'Yves Thériault ", dans Voix ot Images du Pays VII. p. 13-49.

MAJOR, André, " Thériault ou la honte de la chair ", lo Dovoir, 16 décembre 1967, p. 13.

PERRON, Paul, "Théorie actantielle et processus idéologique: Agaguk d'Yres Thériault *. dans Voix of Images, vol. 4, no 2, décembre 1978, p. 272-299.

ROBIDOUX, Réjean, et André Renaud, le Roman canadien-Irançais du vingtieme siècle, Ottawa, Editions de l'Université d'Ottawa, 1966. Sur Thériault: "Agaguk". p. 92-103.

SIMARD, Jean-Paul, Rituel et langage chez Yves Thériault, Montréal, Fides, 1979.

A.B. 